\title{
How does neighborhood walkability affect obesity? The mediating role of commute mode
}

\section{Wenyue Yang \\ South China Agricultural University \\ yangwenyue900780@163.com}

\author{
Suhong Zhou (corresponding author) \\ Sun Yat-sen University, Guangdong Provincial \\ Engineering Research Center for Public Secu- \\ rity and Disaster \& Guangdong Key Labora- \\ tory for Urbanization and Geo-simulation \\ eeszsh@mail.sysu.edu.cn
}

\author{
Xinyu Zhen \\ South China Agricultural University \\ zhenxinyu960301@126.com
}

\begin{abstract}
The walkability of a neighborhood is closely related to residents' travel behavior and daily life and, ultimately, their health and wellbeing. Although existing studies in this area have reached some enlightening conclusions, few of them have considered residents' travel attitudes and preferences, or the mediating role of commute mode. Do travel attitudes and preferences matter in the relationship between neighborhood walkability and residents being obese? How does commute mode work as a mediator? To answer these questions, based on the 2019 travel survey data in Guangzhou, this paper uses the Multilevel Linear Model (MLM) to examine the association between neighborhood walkability and residents' body mass index (BMI). Furthermore, the Mediation Model is used to identify the mediating role of commute mode in the relationship between walkability and BMI. The results show that (1) travel attitudes and preferences do affect the individual's BMI through the mediator of commute mode. (2) After controlling the individual socio-demographics and travel attitudes and preferences, neighborhood walkability has a significant negative effect on BMI. Meanwhile, walkability has a significant positive effect on the use of non-private motorized commute modes. Non-private motorized commute modes have a significant negative effect on BMI. (3) The mediating effect of commute mode in the relationship of neighborhood walkability with the individual's BMI is significant. The proportion of mediation is $32.90 \%$. Insights into the relationship between neighborhood walkability, commute mode, and individual BMI highlight the importance of walkable neighborhoods that encourage people to use healthy commute modes.
\end{abstract}

Keywords: Walkability, commute mode, body mass index (BMI), mediating effect, Multilevel Linear Model (MLM)

\section{Introduction}

Urban planning has a long-term and structural role in shaping neighborhood walkability through "the D's"-density, diversity, design, destination accessibility, and distance to transit, which has a profound

Copyright 2021 Wenyue Yang, Xinyu Zhen \& Suhong Zhou

http://dx.doi.org/10.5198/jtlu.2021.1948

ISSN: 1938-7849 | Licensed under the Creative Commons Attribution - Noncommercial License 4.0

The Journal of Transport and Land Use is the official journal of the World Society for Transport and Land Use (WSTLUR) and is published and sponsored by the University of Minnesota Center for Transportation Studies.

\section{Article history:}

Received: December 23, 2020

Received in revised form: March

5, 2021

Accepted: March 31, 2021

Available online: June 30, 2021 
effect on public health (Schoner et al., 2018; Smargiassi, et al., 2020; Su, Pi, Xie, Cai, \& Weng, 2017). Motorized mobility in cities greatly affects the health of citizens and is one of the most major health challenges of the 21st century (Bongiorno, Santucci, Kon, Santi, \& Ratti, 2019). In recent decades, like what has been taken place in many Western countries, the built environment and people's travel behavior have taken great changes in urban China with the rapid development of urbanization and motorization, such as wider urban roads, huge blocks in the suburbs, and the increase of travel distance and use of cars (Yang \& Cao, 2018; Zhao, 2013). As a result, lifestyles have gradually become sedentary and the resulting obesity problem is growing dramatically in cities (An, Shen, Yang, \& Yang, 2019; Frank, Iroz-Elardo, MacLeod, \& Hong, 2019; Sun, Yan, \& Zhang, 2017).

Obesity is a leading cause of morbidity worldwide and is linked to various long-term adverse health outcomes such as hypertension, diabetes, cardiovascular disease, and certain types of cancer (An et al., 2019; Bodea, Garrow, Meyer, \& Ross, 2009; Jones, 2015; Xu \& Wang, 2015). Rising obesity rates, declining physical activity, and growing rates of chronic disease are major concerns in China (Day, 2016). Based on the 2015 Report on adult obesity in China, the prevalence of overweight adults grew from $22.8 \%$ in 2002 to $30.1 \%$ in 2012 for adults aged $\geq 18$ years, and the prevalence of adult obesity increased from $7.1 \%$ to $11.9 \%$ during the same period (Chinese Center for Disease Prevention, 2015). To our knowledge, although previous studies have already identified the link between built environments and obesity, very few studies have measured the walkability around neighborhoods, which is different from the built environment (Frank et al., 2010; Leslie et al., 2007; Shashank \& Schuurman, 2019). Moreover, individual travel attitudes and preferences and the mediating role of travel mode haven't been sufficiently analyzed in this field of study. To fill these research gaps, we take Guangzhou, China as the study area and travel survey data to explore the effects of neighborhood walkability on individual BMI (Body Mass Index), considering travel attitudes and preferences and the mediation effect of commute mode. We primarily try to answer the following two questions: (1) Do travel attitudes and preferences and neighborhood walkability affect the individual's BMI? And, (2) does commute mode play a mediating role in the association between neighborhood walkability and individual BMI?

The rest of this paper is organized as follows. In section 2, we briefly review previous research on built environments and walkability and their relationship with individual obesity. Section 3 introduces the study area, the neighborhoods we surveyed, the data, and the study methods used in this analysis. Section 4 presents the results of the models and analyzes the effects of neighborhood walkability on individual BMI. Section 5 summarizes the main conclusions with recommendations for planning and policy development.

\section{$2 \quad$ Literature review}

The concept of "walkability" is used to identify the extent to which the objective physical characteristics of a neighborhood built environment may be conductive or not to walking behavior (Frank et al., 2010; Leslie et al., 2007; Shashank \& Schuurman, 2019). It is a measure of whether the built environment supports and encourages walking and can be used to predict the levels of physical activity and active travel, which is considered a crucial aspect of urban planning and design (Cervero \& Kockekman, 1997; Golan, Wilkinson, Henderson, \& Weverka, 2019; Sallis, Frank, Saelens, \& Kraft, 2004; Wang \& Yang, 2019; Weng et al., 2019; Yencha, 2019). Improving neighborhood walking environment (walkability) might positively affect walking behavior, increasing pedestrian activities (such as the number of walking trips, walking duration, pedestrian volumes, walking experience), improving the health of residents, and promoting the sustainable development of society (Bödeker, Finne, Kerr, \& Bucksch, 2018; Cambra \& Moura, 2020; Mytton et al., 2018; Smart, 2018). 
Numerous studies have already investigated the association between the built environment and individual BMI, most of which mainly focused on the accessibility to facilities, density, land-use mix, street connectivity, et al (Adlakha \& Parra, 2020; Munshi, 2016; Sun \& Yin, 2018; Zhao \& Kaestner, 2010). Matozinhos et al. (2015) noted that the number of healthy food stores, the number of restaurants, and the number of places available for physical activity has a significant negative influence on the likelihood of obesity. Likewise, Sarkar, Gallacher, and Webster's study (2013) showed that individual BMI was significantly associated with a number of built environment elements such as land-use mix, density, and street network accessibility. Black, Macinko, Dixon, and Fryer's (2010) study in New York City confirmed that obesity was significantly correlated with neighborhood built environments like the availability of supermarkets and fast food stores. In terms of population density, a study based on the Atlanta SMARTRAQ travel survey by Bodea et al. (2009) showed that residents who live in neighborhoods with higher residential densities are 1.3 times less likely to be overweight and 1.5 times less likely to be obese. Similarly, a study in San Francisco showed that population density was negatively associated with individual BMI (Pendola \& Gen, 2007). However, in the context of dense urban China, Sun et al. (2017) found that population density is positively associated with individual BMI. There were some commonalities in the relationship between street connectivity and individual BMI. Bodea et al. (2009) also found that residents who live in a neighborhood with a more connected street network are 1.2 times less likely to be overweight and 1.1 times less likely to be obese. Based on the Behavioral Risk Factor Surveillance System data, Xu, Wen, and Wang (2015) and Wang, Wen, and Xu (2013) found that poor street connectivity has a significant positive effect on individual obesity in more urbanized areas. Regarding land-use mix, a study in the United States showed that land-use mix was most closely related to obesity, which suggested that residents who lived in neighborhoods with high land-use mix generally had a reduced probability of obesity. However, a study in Wuhan, China, confirmed that the land-use mix was associated with a lower risk of obesity among men, but played an insignificant role for women (Zhou et al., 2017).

Although the above literature studied the built environment elements related to walking respectively and reached some conclusions, other scholars suggested measuring the walkability and its combined impact on physical activity and health would be more insightful and academically valuable (van Cauwenber, Van Holle, De Bourdeaudhuij, Van Dyck, \& Deforche, 2016; Watson et al., 2020; Wey \& Chiu, 2013). Frank, Kerr, Sallis, Miles, and Chapman (2008) revealed that people who lived in walkable neighborhoods were more likely to walk, and the association of walkability with physical activities and BMI was different by sociodemographic subgroups. Some studies have proved that walkability can increase physical activity, thus reducing the likelihood of being overweight or obese (Adlakha, Hipp, \& Brownson, 2016; Boisjoly, El-Geneidy, \& Wasfi, 2018; Tuckel \& Milczarski, 2015). Based on panel data spanning 1999 to 2013 from the U.S. Panel Study of Income Dynamics, a study by Smart (2018) showed a quantitative relationship exists between walkability and individual BMI: residents who moved from the worst to the best walking environment had a decrease in body mass of about 2 pounds. Kowaleski-Jones et al. (2018) found that there was an inverse relationship between neighborhood walkability and individual BMI in Salt Lake County, Utah, which meant that the likelihood of being obese for residents living in a more walkable neighborhood decreased. Evidence suggests walkability was negatively associated with overweight and obesity, but which was positively associated with the waist-to-hip ratio (Nichani, Turley, Vena, \& McCornack, 2020). Likewise, the study in Adelaide, Australia has not observed statistically significant associations between local-area walkability and waist circumference (Sugiyama et al., 2016). In general, most of these studies only measured the direct effect of walkability and the mediating effect of physical activity on individual BMI. Other potential mediators like commute mode might also play a role in the conduction of the influence mechanism. What's more, the relationship between neighborhood walkability and obesity is not consistent in different countries or regions. 
As some studies show, travel attitudes and preferences are significant for travel behavior (Hamidi, \& Zhao, 2020; van de Coevering, Maat, \& Van Wee, 2018). Individuals who prefer walking/biking were found to engage in non-motorized travel, by the contrary, those who prefer a private car have more share of motorized travel time (Lin, Wang, \& Guan, 2017). Moreover, travel attitudes and preferences are significant determinants of individual health. Stark, Singleton, and Uhlmann (2019) found that psychological well-being was positively related to active travel and individual preferences and attitudes towards active modes. Kjær, Højgaard, \& Gyrd-Hnsen (2019) measured the effects of preferences for physical activity on physical exercise in Denmark and found that perceived negative preference for exercise is a barrier to not participating in physical activity. The findings confirmed that a strong preference for walking resulted in a higher walking frequency, resulting in lower obesity prevalence (Frank, Saelens, Powell, \& Chapman, 2007; Lindelöw, Svensson, Brundell-Freij, \& Hiselius, 2017). However, cities in China differ significantly in built environment characteristics from that in the Western countries, as well as people's travel behavior and preferences (Wang \& Lin, 2014; Yang \& Cao, 2018; Yang, Chen, $\&$ Wang, 2020). Therefore, it's necessary to study the relationship between neighborhood walkability and individual BMI in the context of China. In the meanwhile, the mediating role of mode choice was seldom considered in existing studies. It may bias the modeling results if we don't consider it and ignore this important influence. This would also possibly misguide the land use and transport planning and relevant policy-making in the future. Apart from that, few studies have considered the effects of individuals' travel attitudes and preferences, which may also affect the mode choice and walking behavior, and ultimately influence the outcome of people's health (Marquez, Macea, \& Soto, 2019; Schneider, \& Stefanich, 2018; Wee \& Ettema, 2016). Therefore, it is of great significance to examine the effect of neighborhood walkability on individual BMI considering the mediating role of commute mode and the effect of travel attitudes and preferences in this paper.

\section{$3 \quad$ Methodology}

\subsection{The study area and the neighborhoods surveyed}

Guangzhou is one of the megacities with a high-density characteristic in China, which total population was 14.90 million and residential density had reached 14.1 thousand people $/ \mathrm{km}^{2}$ in 2018 . Also, it locates in a coastal region with a subtropical monsoon climate. This geographical environment is likely to affect people's willingness to walk, especially in the long and hot summer. In the meantime, it was reported that the obesity rate in Guangzhou in 2011 reached 20.4\%, which was much higher than the national average (Administration of Sports of Guangdong Province, 2011). Therefore, it's pretty interesting and enlightening to conduct an empirical study on walkability and resident's BMI using Guangzhou as a study area. To make the survey neighborhood evenly distributed, we selected 18 neighborhoods in Guangzhou to perform the survey, of which 9 neighborhoods from the central urban area and suburban area respectively. In addition, to ensure the scientificity and preciseness of the questionnaire data and statistical analysis, we selected neighborhoods with significant differences in walkability (Figure 1 and Table 2).

A pre-survey exercise was conducted in March 2019. Then we amended and refined the questionnaire and carried out the formal survey in April 2019. Residents aged 16 and older were selected to interview. The total number of questionnaires we collected was 1845, of which 1470 were valid (Table 1). Of this number, 375 were individuals 16 years old and older who did not report their height and weight, determinants of the BMI for adults. 


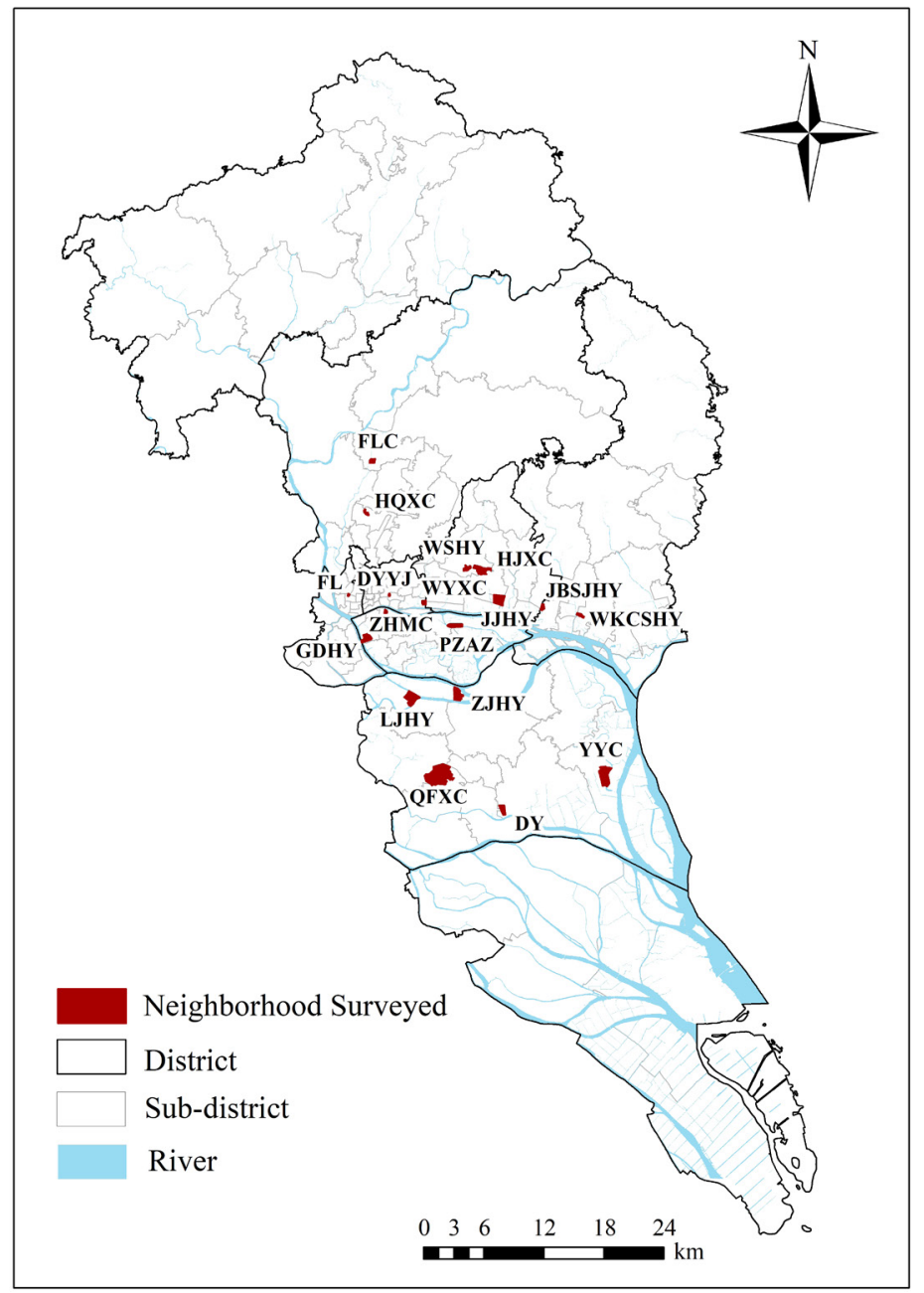

Figure 1. Spatial distribution of the neighborhoods surveyed

\subsection{Variables and data}

Individual BMI was the dependent variable in this study, which was calculated by the following formula: BMI $=$ mass $(\mathrm{kg}) /$ height $\left(\mathrm{m}^{2}\right)$. Commute mode was set as the mediating variable we focused on in the modeling. According to the consumption of physical activity, referring to the classification methods of Hoffmann, Abraham, Skippon, and White (2018) and Sun et al. (2017), this paper divided the commute mode into two types. One of the commute modes was non-private motorized travel that involves more physical activities, including walking, cycling, and public transportation. The other mode was private motorized travel involving less physical activity, including taking a car, taxi, or electric bicycle. The independent variables in this paper included residents' socio-demographics, and travel attitudes and preferences, which were collected through the questionnaire (Table 1), as well as the neighborhood walkability index we measured through GIS technology. Specifically, the residents' socio-demographic attributes that we surveyed included gender, age, education, household monthly income per capita (Income), household size (HS), whether having a child under 16 (Child), Hukou, and whether having a car (CAR). Residents' travel attitudes and preferences included seven variables: the extent of the importance of low-carbon, green, and environmentally friendly travel (AP1), the extent of the importance of owing 
the car to symbolize status (AP2), the degree of preference for sports and exercise (AP3), the degree of preference for traveling by foot or bicycle (AP4), the degree of preference for traveling by bus or metro (AP5), the degree of preference for traveling by car (AP6), and the degree of preference for living near the workplace (AP7). Each travel attitude and preference was assigned a value of 1-5 according to the extent of importance or preference, from the lowest to the highest. Besides, we measure the number of metro stops within the $400 \mathrm{~m}$ buffer zone of the neighborhood boundary (NMS).

Table 1. Distribution of socio-demographics for the sample population

\begin{tabular}{|c|c|c|c|}
\hline Variable & Level & Number of samples & Percent $(\%)$ \\
\hline \multirow[t]{2}{*}{ Gender } & 0 for male & 777 & 52.86 \\
\hline & 1 for female & 693 & 47.14 \\
\hline \multirow[t]{6}{*}{ Age } & 1 represents age $16-24$ & 273 & 18.57 \\
\hline & 2 represents age $25-34$ & 596 & 40.54 \\
\hline & 3 represents age $35-44$ & 441 & 30.00 \\
\hline & 4 represents age $45-54$ & 133 & 9.05 \\
\hline & 5 represents age $55-64$ & 18 & 1.22 \\
\hline & 6 represents age $\geq 65$ & 9 & 0.62 \\
\hline \multirow[t]{5}{*}{ Education } & 1 represents the junior middle school and below & 77 & 5.23 \\
\hline & 2 represents senior high school & 224 & 15.24 \\
\hline & 3 represents junior college & 342 & 23.27 \\
\hline & 4 represents a bachelor's degree & 680 & 46.26 \\
\hline & 5 represents a master's degree or above & 147 & 10.00 \\
\hline \multirow[t]{7}{*}{ Income } & 1 represents income $\leq 3000 \mathrm{RMB}$ & 44 & 2.99 \\
\hline & 2 represents income 3000-3999 RMB & 105 & 7.14 \\
\hline & 3 represents income $4000-5999 \mathrm{RMB}$ & 236 & 16.05 \\
\hline & 4 represents income 6000-7999 RMB & 285 & 19.39 \\
\hline & 5 represents income 8000-9999 RMB & 245 & 16.67 \\
\hline & 6 represents income $10,000-15,000 \mathrm{RMB}$ & 265 & 18.03 \\
\hline & 7 represents income $\geq 15,000 \mathrm{RMB}$ & 290 & 19.73 \\
\hline \multirow[t]{5}{*}{ HS } & 1 represents 1 people & 83 & 5.65 \\
\hline & 2 represents 2 people & 203 & 13.81 \\
\hline & 3 represents 3 people & 510 & 34.69 \\
\hline & 4 represents 4 people & 415 & 28.23 \\
\hline & 5 represents $\geq 5$ people & 259 & 17.62 \\
\hline \multirow[t]{2}{*}{ Child } & 0 for no & 683 & 46.46 \\
\hline & 1 for yes & 787 & 53.53 \\
\hline \multirow[t]{2}{*}{ Hukou } & 0 for other cities & 594 & 40.41 \\
\hline & 1 for Guangzhou & 876 & 59.59 \\
\hline \multirow[t]{2}{*}{ CAR } & 0 for no & 468 & 31.84 \\
\hline & 1 for yes & 1002 & 68.16 \\
\hline \multirow[t]{2}{*}{ Commute mode } & 0 for private motorized travel & 350 & 23.81 \\
\hline & 1 for non-private motorized travel & 1120 & 76.19 \\
\hline
\end{tabular}




\subsection{Calculation of walkability}

The neighborhood walkability was calculated by methods similar to those proposed in previous studies (Frank et al., 2010; Mavoa, Eagleson, Badland, \& Gunn, 2018; Van Cauwenberg et al., 2016). Residential density (RD), land-use mix (LUM), and road intersection density (RID) were used to measure the variable of neighborhood walkability within the neighborhood boundaries in this paper. Specifically, we calculated the RD by the number of residents divided by the area. LUM was calculated by the method of existing studies with thirteen types of Points of Interest (POIs) (Moniruzzaman, Páez, Nurul, \& Morency, 2013; Yang \& Cao, 2018). RID was measured based on kernel density estimation. A road intersection was defined as the junction of three or more road segments. The data of POIs and road networks were collected from Open Street Map (OSM). Then, we used the z-score method to calculate each of the three indexes, and the walkability variable was calculated by the following formula (Shashank \& Schuurman, 2019; van Cauwenberg et al., 2016), in which the weight for these three variables are 1 by considering the reality of China and references of Yang, Zhen, Gao, and Ouyang (2020) and Frank et al. (2007) studies:

Walkability $=(z-R D)+(z-L U M)+(z-R I D)$

$z=\frac{\chi-\mu}{\delta}$

where $\chi$ represents the observations (we focus on three indexes of the neighborhood walkability respectively, including RD, LUM, and RID in this paper), $\mu$ is the average of the observations, and $\delta$ is the standard deviation of the observations. 
Table 2. Walkability characteristics for the neighborhoods surveyed

\begin{tabular}{|c|c|c|c|c|c|c|}
\hline Neighborhood & District & $\begin{array}{l}\text { RD (Residen- } \\
\text { tial Density) } \\
\left(\text { Person } / \mathrm{km}^{2}\right)\end{array}$ & $\begin{array}{l}\text { LUM (Land- } \\
\text { Use Mix) }\end{array}$ & $\begin{array}{l}\text { RID (Road } \\
\text { Intersection } \\
\text { Density) } \\
(\text { Unit/km²) }\end{array}$ & Walkability & $\begin{array}{l}\text { NMS (Num- } \\
\text { ber of Metro } \\
\text { Stop) }\end{array}$ \\
\hline $\begin{array}{l}\text { ZHMD (Zhong- } \\
\text { haimingdu) }\end{array}$ & Haizhu & 66700.44 & 0.46 & 103.38 & 2.83 & 0 \\
\hline $\begin{array}{l}\text { WYXC (Wuyangxin- } \\
\text { cun) }\end{array}$ & Yuexiu & 32611.93 & 0.54 & 97.18 & 2.31 & 1 \\
\hline $\begin{array}{l}\text { WSHY (Wushanhua- } \\
\text { yuan) }\end{array}$ & Tianhe & 31846.49 & 0.22 & 54.30 & -0.95 & 1 \\
\hline PZAZ (Pazhouanzhi) & Haizhu & 12331.93 & 0.37 & 56.17 & -0.47 & 2 \\
\hline JJHY (Junjinghuayuan) & Tianhe & 13827.30 & 0.36 & 83.52 & 0.21 & 3 \\
\hline $\begin{array}{l}\text { HJXC (Huijingx- } \\
\text { incheng) }\end{array}$ & Tianhe & 8292.46 & 0.11 & 23.56 & -3.09 & 0 \\
\hline $\begin{array}{l}\text { GDHY (Guangdahua- } \\
\text { yuan) }\end{array}$ & Haizhu & 32147.42 & 0.18 & 61.01 & -1.03 & 0 \\
\hline FL (Fuli) & Haizhu & 114489.00 & 0.54 & 150.87 & 5.92 & 0 \\
\hline DYYJ (Dongyueyaju) & Yuexiu & 141556.73 & 0.11 & 132.54 & 3.31 & 1 \\
\hline $\begin{array}{l}\text { ZJHY (Zhujianghua- } \\
\text { yuan) }\end{array}$ & Panyu & 2317.01 & 0.07 & 19.36 & -3.67 & 0 \\
\hline YYC (Yayuncheng) & Panyu & 2895.53 & 0.51 & 12.52 & -0.86 & 0 \\
\hline $\begin{array}{l}\text { WKCSHY (Wangkech- } \\
\text { engshihuayuan) }\end{array}$ & Huangpu & 29717.01 & 0.25 & 35.44 & -1.30 & 2 \\
\hline QFXC (Qifuxincun) & Panyu & 6980.12 & 0.25 & 13.52 & -2.48 & 0 \\
\hline LJHY (Lijianghuayuan) & Panyu & 9988.76 & 0.41 & 59.50 & -0.15 & 1 \\
\hline $\begin{array}{l}\text { JBSJHY (Jinbishijihua- } \\
\text { yuan) }\end{array}$ & Huangpu & 63149.01 & 0.40 & 34.14 & 0.61 & 0 \\
\hline $\begin{array}{l}\text { HQXC (Huiqiaox- } \\
\text { incheng) }\end{array}$ & Baiyun & 51171.10 & 0.41 & 107.94 & 2.22 & 0 \\
\hline FLC (Fulicheng) & Baiyun & 19364.09 & 0.27 & 27.26 & -1.65 & 0 \\
\hline DY (Dongyi) & Panyu & 20503.25 & 0.57 & 22.45 & 0.28 & 1 \\
\hline
\end{tabular}

\subsection{Multilevel Linear Model (MLM)}

We employed the Multilevel Linear Model (MLM) in this paper to examine the complex association between neighborhood walkability, travel attitudes and preferences, commute mode, and individual BMI. The variables used in this paper constituted multilevel data. The variables of BMI, commute mode, socio-demographics, and travel attitudes and preferences of residents constitute non-aggregated data at the individual level, while the variable of walkability and the number of metro stops constitute aggregated data at the neighborhood level. Based on this, if data with a multilevel structure is only considered to be processed on a single level, it is likely to produce excessive errors and biased parameter estimates. Therefore, it is necessary to build a multilevel model to distinguish the total variation of multilevel on two levels - within the group and between-group—in analyzing the dependent variables. Independent variables were introduced at different levels to explain the variation of within-group and between-group, from which we can obtain more reliable estimation results (Stephen \& Anthony, 2002; Peugh, 2010; Xie, 2013). 
To explore the impact of travel attitudes and preferences on individual BMI, and the mediating role of commute mode in the relationship between neighborhood walkability and BMI, the MLM was constructed in three steps. Firstly, we constructed the Null Model for individual BMI and commute mode, respectively, to judge whether there is significant variation at the neighborhood level and individual level. Secondly, to explore the impact of the independent variables with multilevel data on individual BMI and commute mode, and to ensure the robustness of the model estimation, we constructed Random Intercept Models 1-4 on individual BMI and Random Intercept Models 5-6 on commute mode, respectively. Thirdly, we constructed a Mediation Model to measure whether commute mode plays a mediating role in the relationship between neighborhood walkability and individual BMI.

\subsubsection{Null Model}

The Null Model is the origin of MLM, which contains no explanatory variables at all. Through variance contribution, the Null Model can be used to produce an estimate of the intra-class correlation coefficient (ICC) to measure the proportion of variance between groups in the total variance (Joop, Mirjam, \& Rens, 2018). The Null Model for individual BMI can be expressed as follows:

At the individual level:

$y_{i j}=\beta_{0 j}+\varepsilon_{i j}$

At the neighborhood level:

$\beta_{0 j}=\gamma_{00}+\mu_{0 j}$

The full formula of Null Model:

$y_{i j}=\gamma_{00}+\mu_{0 j}+\varepsilon_{i j}$

where $y_{i j}$ refers to individual BMI of resident $i$ living in neighborhood $j ; \beta_{0 j}$ is the mean BMI for neighborhood $j, \gamma_{00}$ is the overall average or intercept of the dependent variable; $\mu_{0 j}$ is the random effect of neighborhood $j$ representing the distance of the intercept of the neighborhood $j$ to the intercept of the overall sample, which represents the deviance between the average of the BMI of the residents in the neighborhood $j$ and all sample neighborhoods; $\varepsilon_{i j}$ is the random variable of resident $i$ representing the deviance between resident $i$ and the intercept of the neighborhood $j$.

Finding the variance on both sides, the equation reads:

$\operatorname{Var}\left(y_{i j}\right)=\operatorname{Var}\left(\mu_{0 j}+\varepsilon_{i j}\right)=\tau_{00}+\sigma^{2}$

The next step in the Null Model is to explain the variation between individual level and neighborhood level, for the ICC

$\rho=\tau_{00} /\left(\tau_{00}+\sigma^{2}\right)$

where $\tau_{00}$ refers to the variance of the variable at the neighborhood level, representing the variation among the variables at the neighborhood level; $\sigma^{2}$ refers to the variance of the variable at the individual level, representing the variation among the variables at the individual level; $\tau_{00}+\sigma^{2}$ is the total variance of the Null Model. 


\subsubsection{Random Intercept Model}

After estimating the degree of variation at the individual level and neighborhood level, we build an explanatory model to explain the variation, that is, which variables at the individual level and neighborhood level, and to what extent, affect the BMI and commute mode of residents. In the Random Intercept Model, the variables in the level 1 model are defined as those of the individual level, including residential socio-demographic attributes and travel attitudes and preferences. The variable in the level 2 model is defined as that at the neighborhood level, namely the neighborhood walkability and the number of metro stops. The specific model structure is as follows:

At the individual level:

$Y_{i j}=\beta_{0 j}+\beta_{1 j} X_{1 i j}+\beta_{2 j} X_{2 i j}+\cdots+\beta_{q j} X_{q i j}+r_{i j}$

At the neighborhood level:

$\beta_{0 j}=\gamma_{00}+\gamma_{01} W_{1 j}+\gamma_{02} W_{2 j}+\cdots+\gamma_{0 S} W_{S j}+\mu_{0 j}$

$\beta_{1 j}=\gamma_{10}$

$\beta_{2 j}=\gamma_{20}$

...

$\beta_{q j}=\gamma_{q 0}$

Substituting Equation (9) into Equation (8) yields the combined model:

$Y_{i j}=\gamma_{00}+\sum_{(q=1)}^{q}\left(\beta_{q j} X_{q i j}\right)+\sum_{(s=1)}^{s} \gamma_{0 S} W_{S j}+r_{i j}+\mu_{0 j}$

where $Y_{i j}$ refers to individual BMI of resident i living in neighborhood $j ; X_{q i j}$ refers to the value of explanatory variables $q$ of resident $\mathrm{i}$ living in the neighborhood $j$, including the variables of socio-demographic attributes and travel attitudes and preferences in this model; $W_{S j}$ is neighborhood walkability and the number of metro stops; $\beta_{0 j} \beta_{1 j^{\prime}} \beta_{2 j^{\prime}} \cdots, \beta_{q j}$ are the random intercept in the individual level; $\gamma_{0 S}$ is the regression coefficient; $r_{i j}$ is the random effect of the individual level, subordinated to $N\left(0, \sigma^{2}\right)$; $\mu_{0 j}$ is the random error of the neighborhood level, subordinated to $N\left(0, \tau_{00}\right)$.

Model 1 only considers the variables of socio-demographic attributes and travel attitudes and preferences at the individual level of the sample, and Model 2 adds the variables of residents' commute mode based on Model 1 to test whether commute mode has a significant impact on individual BMI without considering neighborhood walkability and the number of metro stops. Model 3 adds the variables of neighborhood walkability and the number of metro stops based on Model 1 to explore whether neighborhood walkability and the number of metro stops have a significant impact on the BMI of residents without considering the commute mode. Based on Model 1, the commute mode, the neighborhood walkability, and the number of metro stops are added at the same time to explore whether the commute mode has a significant impact on the individual BMI or neighborhood walkability has a significant impact on the individual BMI in Model 4.

Besides, to explore the impact of neighborhood walkability on commute mode, this paper constructed two Random Intercept Models with the same idea. Among them, only the variables of sociodemographic and travel attitudes and preferences at the individual level were added to Model 5, and the neighborhood walkability and the number of metro stops were added to Model 6 to explore whether neighborhood walkability has a significant impact on the commute mode of residents. In Models 2-4 and Model 6, the variables at the individual level only acted as control variables in the model construction. 


\subsubsection{Mediation Model}

In the Mediation Model, assuming that commute mode has a mediating effect between neighborhood walkability and the BMI of the residents, we build the following model for the commute mode of the residents (Fang, Wen, Zhang, \& Ren, 2014; Matsumura, Garnier, \& Spybrook, 2013):

At the individual level:

$M_{i j}=\beta_{0 j}+\varepsilon_{i j}$

At the neighborhood level:

$\beta_{0 j}=\gamma_{00}+\gamma_{01}^{a} X_{j}+\mu_{0 j}$

where $i$ represents resident; jrepresents neighborhood; $\gamma_{01}^{a}$ is the path coefficient from the independent variable of neighborhood walkability $X_{j}$ to the mediating variable of commute mode $M_{i j}$, whose effect is namely as $\mathrm{A} ; \beta_{0 j}$ and $\gamma_{00}$ represents the residuals at the individual and neighborhood level, respectively.

Subsequently, we explore the influence path of the mediating variable of commute mode M_ij on the dependent variable of individual BMI. The specific model structure is as follows:

At the individual level:

$Y_{i j}=\beta_{0 j}+\beta_{1 j}\left(M_{i j}-\bar{M}_{j}\right)+\varepsilon_{i j}$

At the neighborhood level:

$\beta_{0 j}=\gamma_{00}+\gamma_{01}^{c^{\prime}} X_{j}+\gamma_{02} \bar{M}_{j}+\mu_{0 j}$

$\beta_{1 j}=\gamma_{10}^{b}$

where $\bar{M}_{j}$ is the group mean of mediating variable $M_{i j}$; the regression coefficient $\gamma_{10}^{b}$ represents the within-group variation $\left(M_{i j}-\bar{M}_{j}\right)$ of the mediation variable $M_{i j}$, whose effect is named as $\mathrm{B}$; the regression coefficient $\gamma_{02}$ represents the effect of between-group $\bar{M}_{j}$ of the mediating variable $M_{i j}$; the mediating effect of $M_{i j}$ can be represented as $\mathrm{AB}=\gamma_{01}^{a}{ }^{*} \gamma_{02}$. If the value and the confidence interval of $\mathrm{AB}$ do not include 0 , it means that the mediating effect is significant (Fang, Wen, Zhang, \& Ren, 2014).

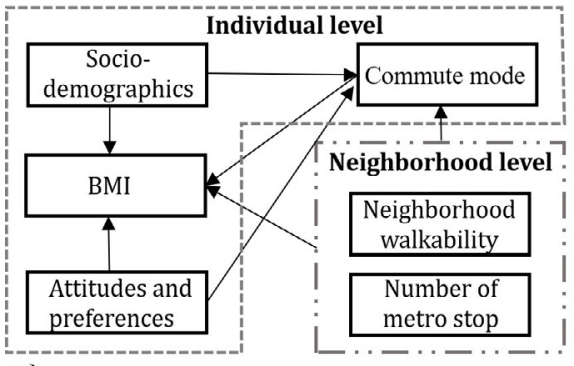

a)

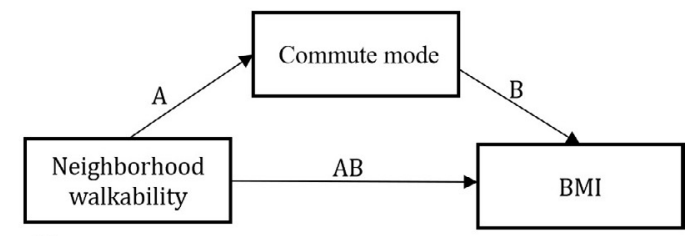

b)

Figure 2. The conceptual framework for the MLM

Models estimation was performed using $\mathrm{R}$ version 3.6.1. The overall relationships among neighborhood walkability, the number of metro stops, individual BMI, and commute mode were analyzed using the Random Intercept Model using the lme4 package with Restricted Estimation Maximum 
Likelihood. Multilevel mediation analyses were performed using a mediation package with the Bootstrap method.

\section{$4 \quad$ Results}

\subsection{Results of the Null Model}

Table 3 shows the results of the Null Model of individual BMI and commute mode. It can be seen that the ICC of the Null Model of the individuals' BMI and commute mode are 0.062 and 0.218 , respectively; that is, $6.2 \%$ of variation of individual BMI and $21.8 \%$ variation of commute mode can be explained by the variables at the neighborhood level, and the remaining $93.8 \%$ (BMI) and 78.2\% (commute mode) of variation can be explained by the variables at the individual level. According to the study by Cohen (1988), if ICC is greater than 0.059 , the data can be considered to be nested and inter-group variation cannot be ignored, indicating that it is necessary to take an inter-group effect into account in the Random Intercept Model. Therefore, a Random Intercept Model is built to estimate which variables affect individual BMI and commute mode.

Table 3. Null Model analysis of individual BMI and commute mode at the neighborhood and individual level

\begin{tabular}{lll}
\hline Parameter & Null Model of individual BMI & Null Model of commute mode \\
\hline $\begin{array}{l}\text { Standard deviation at the neighbor- } \\
\text { hood level }\end{array}$ & 0.192 & 0.115 \\
$\begin{array}{l}\text { Standard deviation at the individual } \\
\text { level }\end{array}$ & 2.891 & 0.413 \\
ICC & 0.062 & 0.218 \\
$\begin{array}{l}\text { Neighborhood sample } \\
\text { Individual sample }\end{array}$ & 18 & \\
\hline
\end{tabular}

\subsection{Effects of variables at the individual level on BMI and commute mode}

The model results in Table 4 show that the effects of the variables of socio-demographic and travel attitudes and preferences at the individual level on individual BMI are the same in Models 1-4. This meant that the model estimation results are robust. Travel attitudes and preferences had no significant direct impact on individual BMI. For the socio-demographic attributes, the variables of gender, age, and whether having a child under 16 had a significant effect on individual BMI at the $0.1 \%$ level. Specifically, males and elders and residents with a child under 16 years old tended to be obese, but education, income, household size, Hukou, and whether having a car had no significant effect on individual BMI. The estimation results of the above influencing factors at the individual level are consistent with existing research (Black et al., 2010; Liao et al., 2016). Therefore, we will not further analyze it in detail in this paper. 
Table 4. Model estimation results of residents' BMI by Random Intercept Model

\begin{tabular}{|c|c|c|c|c|}
\hline \multirow{2}{*}{ Variables } & \multicolumn{4}{|c|}{ Fixed effects (coefficient $(95 \% \mathrm{CI})$ ) } \\
\hline & Model 1 & Model 2 & Model 3 & Model 4 \\
\hline \multicolumn{5}{|c|}{ At the individual level } \\
\hline AP1 & $-0.014(-0.185$ to 0.157$)$ & $-0.011(-0.182$ to 0.160$)$ & $-0.019(-0.190$ to 0.152$)$ & $-0.016(-0.187$ to 0.155$)$ \\
\hline $\mathrm{AP} 2$ & $-0.119(-0.280$ to 0.042$)$ & $-0.124(-0.285$ to 0.037$)$ & $-0.116(-0.277$ to 0.044$)$ & $-0.121(-0.282$ to 0.039$)$ \\
\hline $\mathrm{AP} 3$ & $0.092(-0.089$ to 0.274$)$ & $0.093(-0.089$ to 0.274$)$ & $0.093(-0.088$ to 0.275$)$ & $0.094(-0.087$ to 0.275$)$ \\
\hline AP4 & $-0.042(-0.235$ to 0.150$)$ & $-0.035(-0.227$ to 0.158$)$ & $-0.039(-0.231$ to 0.153$)$ & $-0.032(-0.225$ to 0.160$)$ \\
\hline AP5 & $0.101(-0.080$ to 0.283$)$ & $0.127(-0.056$ to 0.310$)$ & $0.105(-0.076$ to 0.286$)$ & $0.128(-0.056$ to 0.311$)$ \\
\hline AP6 & $-0.068(-0.253$ to 0.117$)$ & $-0.095(-0.283$ to 0.092$)$ & $-0.075(-0.260$ to 0.110$)$ & $-0.099(-0.286$ to 0.089$)$ \\
\hline AP7 & $-0.150(-0.335$ to 0.037$)$ & $-0.145(-0.330$ to 0.040$)$ & $-0.146(-0.332$ to 0.039$)$ & $-0.143(-0.328$ to 0.043$)$ \\
\hline Gender & $\begin{array}{l}-2.153^{* * *}(-2.424 \text { to } \\
-1.883)\end{array}$ & $\begin{array}{l}-2.137^{* * *}(-2.408 \text { to } \\
-1.865)\end{array}$ & $\begin{array}{l}-2.149^{* * *}(-2.420 \text { to } \\
-1.879)\end{array}$ & $\begin{array}{l}-2.135^{* * *}(-2.406 \text { to } \\
-1.864)\end{array}$ \\
\hline Age & $\begin{array}{l}0.652^{* * *}(0.505 \text { to } \\
0.800)\end{array}$ & $\begin{array}{l}0.632^{* * *}(0.483 \text { to } \\
0.780)\end{array}$ & $\begin{array}{l}0.657^{* * *}(0.510 \text { to } \\
0.804)\end{array}$ & $\begin{array}{l}0.639^{* * *}(0.490 \text { to } \\
0.787)\end{array}$ \\
\hline Education & $-0.054(-0.195$ to 0.086$)$ & $-0.059(-0.200$ to 0.081$)$ & $-0.059(-0.199$ to 0.082$)$ & $-0.064(-0.204$ to 0.077$)$ \\
\hline Income & $0.057(-0.029$ to 0.143$)$ & $0.047(-0.040$ to 0.134$)$ & $0.057(-0.029$ to 0.143$)$ & $0.048(-0.039$ to 0.135$)$ \\
\hline HS & $-0.022(-0.155$ to 0.112$)$ & $-0.022(-0.155$ to 0.111$)$ & $-0.024(-0.157$ to 0.109$)$ & $-0.024(-0.157$ to 0.109$)$ \\
\hline Child & $\begin{array}{l}0.530^{* * *}(0.229 \text { to } \\
0.831)\end{array}$ & $\begin{array}{l}0.524^{* * *}(0.223 \text { to } \\
0.825)\end{array}$ & $\begin{array}{l}0.516^{* * *}(0.215 \text { to } \\
0.818)\end{array}$ & $\begin{array}{l}0.511^{\text {*** }}(0.209 \text { to } \\
0.812)\end{array}$ \\
\hline Hukou & $-0.045(-0.328$ to 0.238$)$ & $-0.040(-0.323$ to 0.243$)$ & $-0.026(-0.310$ to 0.257$)$ & $-0.023(-0.306$ to 0.261$)$ \\
\hline CAR & $-0.004(-0.316$ to 0.308$)$ & $-0.053(-0.369$ to 0.263$)$ & $-0.023(-0.334$ to 0.289$)$ & $-0.065(-0.381$ to 0.251$)$ \\
\hline Commute mode & & $\begin{array}{l}-0.323^{\#}(-0.671 \text { to } \\
0.024)\end{array}$ & & $-0.283(-0.634$ to 0.673$)$ \\
\hline \multicolumn{5}{|c|}{$\begin{array}{l}\text { At the neighborhood } \\
\text { level }\end{array}$} \\
\hline Walkability & & & $\begin{array}{l}-0.066^{\#}(-0.138 \text { to } \\
0.006)\end{array}$ & $\begin{array}{l}-0.060^{\#}(-0.132 \text { to } \\
0.011)\end{array}$ \\
\hline NMS & & & $-0.067(-0.231$ to 0.097$)$ & $-0.058(-0.219$ to 0.104$)$ \\
\hline \multicolumn{5}{|c|}{$\begin{array}{l}\text { Goodness-of-fit for } \\
\text { model }\end{array}$} \\
\hline Log Likelihood & -3497.342 & -3496.511 & -3499.242 & -3498.793 \\
\hline AIC & 7030.684 & 7029.022 & 7028.485 & 7039.586 \\
\hline $\mathrm{BIC}$ & 7125.761 & 7123.368 & 7124.099 & 7150.466 \\
\hline
\end{tabular}

Note: (1) ${ }^{* * *}$ Significant at the $0.1 \%$ level; ${ }^{* *}$ Significant at the $1 \%$ level; ${ }^{*}$ Significant at the $5 \%$ level; ${ }^{*}$ Significant at the $10 \%$ level.

(2) AIC (Akaike Information Criterion) and BIC (Bayesian Information Criterion) are the standards by which to judge whether the goodness-of-fit for the model fits well or not. The model fits well, with the values of AIC and BIC becoming smaller.

Table 5 reflects the model estimation results of the effect of the variables of socio-demographic and travel attitudes and preferences on the commute mode. In general, the estimation results of each variable of Models 5-6 are consistent, so it can be considered that the models are robust. The indirect effects of travel attitudes and preferences on individual BMI came from their impact on commute mode which, in turn, had an impact on individual BMI. Although "the degree of preference for traveling by bus or metro" (AP5) and "the degree of preference for traveling by car" (AP6) had no significant direct effect on individual BMI, they had significant indirect effects on BMI through commute mode. Specifically, 
"the degree of preference for traveling by bus or metro" (AP5) had a positive effect on non-private motorized commute mode at the significance of $0.1 \%$ level while "the degree of preference for traveling by car" (AP6) had a negative effect on non-private motorized commute mode at the significance of $0.1 \%$ level. That is, residents who prefer to commute by bus or metro and do not like to commute by car are more likely to choose non-private motorized commute modes. And non-private motorized commute mode was significantly associated with lower BMI, which led to the significant indirect effects of these two travel attitudes and preferences variables on individual BMI. This is consistent with a study in Sint-Niklaas, Belgium which also found that adults who prefer passive transport will have a low level of physical activity (Bodea et al., 2009). Furthermore, Egset and Nordfærn (2019) confirmed that travel attitudes contributed to explaining the variance of travel mode, thus affecting the level of physical activity. This is probably because residents who tend to commute by non-private motorized travel, such as bus or metro, have a higher level of physical activity than those who prefer to commute by car, thus reducing the likelihood of being obese. Therefore, changing residents' travel preferences, that is, encouraging people to use non-motorized commute modes, is also a very important way to reduce individual obesity and to build a healthy city.

For socio-demographics, the variables of gender, age, education, household monthly income per capita, and whether having a car had a significant effect on the commute mode at the $0.1 \%, 0.1 \%, 10 \%$, $0.1 \%$, and $0.1 \%$ level, respectively. Specifically, females, younger and residents with a lower level of education, lower monthly per capita income, and without a car are more likely to choose a non-private motorized commute mode. However, other travel attitudes and preferences and socio-demographics have no significant impact on the commute mode.

Table 5. Model estimation results of commute mode by Random Intercept Model

\begin{tabular}{|c|c|c|}
\hline \multirow{2}{*}{ Variables } & \multicolumn{2}{|c|}{ Fixed effects (coefficient $(95 \% \mathrm{CI}))$} \\
\hline & Model 5 & Model 6 \\
\hline \multicolumn{3}{|c|}{ At the individual level } \\
\hline AP1 & $0.005(-0.020$ to 0.030$)$ & $0.006(-0.019$ to 0.031$)$ \\
\hline $\mathrm{AP} 2$ & $-0.019(-0.043$ to 0.004$)$ & $-0.019(-0.043$ to 0.004$)$ \\
\hline AP3 & $0.002(-0.024$ to 0.029$)$ & $0.002(-0.024$ to 0.029$)$ \\
\hline $\mathrm{AP} 4$ & $0.019(-0.010$ to 0.047$)$ & $0.019(-0.009$ to 0.047$)$ \\
\hline AP5 & $0.082^{* * *}(0.055$ to 0.108$)$ & $0.081^{* * *}(0.055$ to 0.108$)$ \\
\hline AP6 & $-0.087^{* * *}(-0.114$ to -0.060$)$ & $-0.086^{* * *}(-0.113$ to -0.059$)$ \\
\hline AP7 & $0.010(-0.018$ to 0.037$)$ & $0.010(-0.018$ to 0.037$)$ \\
\hline Gender & $0.055^{* * *}(0.016$ to 0.095$)$ & $0.054^{* * *}(0.015$ to 0.094$)$ \\
\hline Age & $-0.059^{* * *}(-0.080$ to -0.037$)$ & $-0.060^{* * *}(-0.081$ to -0.038$)$ \\
\hline Education & $-0.019^{\#}(-0.040$ to 0.002$)$ & $-0.019^{\#}(-0.039$ to 0.002$)$ \\
\hline Income & $-0.032^{* * *}(-0.046$ to -0.019$)$ & $-0.032^{* * *}(-0.045$ to -0.019$)$ \\
\hline HS & $-0.002(-0.021$ to 0.017$)$ & $-0.002(-0.021$ to 0.018$)$ \\
\hline Child & $-0.013(-0.058$ to 0.031$)$ & $-0.013(-0.058$ to 0.031$)$ \\
\hline Hukou & $0.019(-0.023$ to 0.060$)$ & $0.017(-0.025$ to 0.058$)$ \\
\hline CAR & $-0.152^{* * *}(-0.197$ to -0.106$)$ & $-0.150^{* * *}(-0.195$ to -0.104$)$ \\
\hline \multicolumn{3}{|c|}{ At the neighborhood level } \\
\hline Walkability & & $0.023^{*}(0.005$ to 0.040$)$ \\
\hline NMS & & $0.037^{\#}(-0.007$ to 0.082$)$ \\
\hline
\end{tabular}




\begin{tabular}{lll}
\hline \multirow{2}{*}{ Variables } & \multicolumn{2}{l}{ Fixed effects (coefficient $(95 \%$ CI) } \\
\cline { 2 - 3 } & Model 5 & Model 6 \\
\hline Log Likelihood & -704.9976 & -707.0911 \\
AIC & 1445.995 & 1445.182 \\
BIC & 1541.073 & 1539.796 \\
\hline
\end{tabular}

Note: (1) ${ }^{* * *}$ Significant at the $0.1 \%$ level; ${ }^{* *}$ Significant at the $1 \%$ level; ${ }^{*}$ Significant at the $5 \%$ level; ${ }^{*}$ Significant at the $10 \%$ level.

(2) AIC (Akaike Information Criterion) and BIC (Bayesian Information Criterion) are the standards by which to judge whether the goodness-of-fit for the model fits well or not. The model fits well, with the values of AIC and BIC becoming smaller.

\subsection{Effects of neighborhood walkability and commute mode on individual BMI}

Based on Model 1, the variables of residents' commute mode are added to Model 2. The AIC and BIC of the model are reduced from 7030.684 and 7125.761 to 7029.022 and 7123.368 , respectively, that is, the goodness-of-fit for Model 2 is better than Model 1. It can be seen that the differences in individual BMI can be explained well by the newly added variable commute mode in Model 2. After adding the variable of neighborhood walkability, and the number of metro stops to Model 3 based on Model 1, the AIC and BIC of Model 3 are 7028.485 and 7124.099, respectively, which indicates the goodness-of-fit for Model 3 is better than Model 1. That is neighborhood walkability helps to improve the explanation of the difference in individual BMI. We added the variables of commute mode, neighborhood walkability, and the number of metro stops simultaneously to Model 4. Under the joint influence of variables at the individual neighborhood level, walkability has a significant impact on the BMI of residents, while commute mode has no impact on the BMI of residents. This shows that after controlling sociodemographics and travel attitudes and preferences at the individual level, neighborhood walkability has a significant negative impact on BMI, while the use of non-private motorized commute modes and the number of metro stops have no direct impact on BMI. Therefore, neighborhood walkability relates to lower BMI and obesity risk.

In general, the estimation results of each variable of Models 1-4 are consistent, so it can be considered that the model estimation is robust. The use of non-private motorized commute modes and neighborhood walkability has a significant impact on lower BMI (the significance level was 1\%), which is consistent with existing research (Alfonzo, Guo, Lin, \& Day, 2014; Turrell, Hewitt, Rachele, GilesCorti, \& Brown, 2018).

\subsection{Effects of neighborhood walkability on commute mode}

To explore the impact of neighborhood walkability on commute mode, we added the neighborhood walkability and the number of metro stops to Model 6 based on Model 5. The estimation results of Model 6 show that neighborhood walkability (95\% CI: 0.005 to 0.040 ) and the number of metro stops ( $95 \%$ CI: -0.007 to 0.082 ) have a significant impact on the commute mode of residents, at the $5 \%$ and $10 \%$ significance level respectively (Table 5). At the same time, the estimation results of the variables of residents' travel attitudes and preferences and socio-demographic attributes are consistent with those in Model 5, which shows that the estimation result of Model 6 is reliable. Besides, the AIC and BIC of Model 6 are 1445.182 and 1539.796 respectively, which are smaller than those of Model 5, indicating that the goodness-of-fit for Model 6 is better than that of Model 5, and the explanation of the effect of neighborhood walkability on commute mode is stronger than that of the variables at the individual level. This is consistent with the estimation results in Table 3, which showed that a part of the variation 
of the commute mode of residents can be explained by the variables at the neighborhood level.

On the whole, the estimation results of Model 5 and Model 6 are consistent, so it can be considered that the results of the model estimation are robust. Neighborhood walkability has a significant positive effect on the use of non-private motorized commute modes (the significance level was 5\%). The better the neighborhood walkability, the greater the probability that residents choose non-private motorized commute modes. This conclusion is consistent with existing research (Barnes, Winters, Ste-Marie, Mckay, \& Ashe, 2016; Bödeker et al., 2018; Freeman et al., 2013; Kikuchi et al., 2018; Wasfi, Dasgupta, Eluru, \& Ross, 2016). Specifically, the study of Freeman et al. (2013) in the United States shows that the probability of non-motorized travel increases by $10 \%$ for each unit of increase in walkability. The number of metro stops had a positive effect on non-private motorized commute modes, which indicated that within the tolerant walking distance the number of metro stops increased the probability of non-motorized commute travel and reduced the private car mode. The study in Singapore showed that an increase in rail transit can encourage the switch from private cars to non-private commute mode (Dai, Diao \& Sing, 2020).

\subsection{Mediating effect of commute mode}

This paper implements the Mediation Model to verify whether commute mode plays a mediating role in the relationship between neighborhood walkability and individual BMI. From the results of the Mediation Model shown in Table 6, the average causal mediation effect is -0.022 at the significance of $0.1 \%$, indicating that mediation effect exists and commute mode plays a mediation role in the relationship of neighborhood walkability between individuals BMI. That is, $32.90 \%$ of the effect on the association of neighborhood walkability and individual obesity could be explained by commute mode changes.

Meanwhile, neighborhood walkability has no significant average direct effect on individual BMI after taking into account the mediation effect of commute mode. This indicates that commute mode does mediate the relationship between neighborhood walkability and individual BMI. And the total effect of the association between neighborhood walkability and individual BMI is significant at the level of $10 \%$, which showed that neighborhood walkability works on individuals' BMI by affecting their commute mode. Therefore, improving neighborhood walkability is an essential means to encourage residents to take the initiative to choose a non-private motorized mode to commute, and thus increasing physical activity and reducing the likelihood of being overweight or obese.

Table 6. Results of the Mediation Model

\begin{tabular}{ll}
\hline & Coefficient $(95 \%$ CI $)$ \\
\hline Average Causal Mediation Effect (ACME) & $-0.022^{* * *}(-0.036$ to -0.010$)$ \\
Average Direct Effect (ADE) & $-0.044(-0.109$ to 0.030$)$ \\
Total Effect & $-0.066^{\#}(-0.132$ to 0.000$)$ \\
Proportion of mediation & $0.329(-0.577$ to 1.900$)$ \\
\hline
\end{tabular}

Note: ${ }^{* * *}$ Significant at the $0.1 \%$ level; ${ }^{* *}$ Significant at the $1 \%$ level; ${ }^{*}$ Significant at the $5 \%$ level; ${ }^{*}$ Significant at the $10 \%$ level. 


\section{$5 \quad$ Discussion and conclusions}

\subsection{Conclusions and policy implications}

Understanding the relationship between neighborhood walkability and individual BMI is pretty important because obesity is an increasingly serious problem in public health especially within an urban context. Based on 18 neighborhood survey data of Guangzhou, China, and the Multilevel Linear Model, this paper explores the association between neighborhood walkability and individual BMI. It mainly draws the following conclusions. First, both travel attitudes and preferences and neighborhood walkability were found to have effects on the commute mode. Residents preferring traveling by bus or metro tended to commute by non-private motorized modes (walking, cycling, and public transport) while those preferring traveling by cars tended to commute by private motorized modes. Individuals living in walkable neighborhoods were more likely to use non-private motorized modes to commute regardless of their demographic characteristics and travel attitudes and preferences.

Secondly, commute mode plays a mediation in the relationship between neighborhood walkability and individual BMI. Therefore, the government should develop more policies to encourage the use of walking, cycling, and public transport rather than private cars and the planning should ensure a good travel environment for these modes. What's more, improving neighborhood walkability is beneficial for residents to choose a non-private motorized mode to commute, thus increases their physical activities and energy consumption and leads to a healthy weight. Specifically, improving the connectivity of streets to enhance the accessibility of neighborhoods is conducive to encouraging residents to walk more, thereby reducing the risk of individual obesity. Meanwhile, advocating the high density and the diversity of land use around the neighborhood could help meet the daily needs of residents within a certain range of walking, to reduce the dependence on motorization. Through improving neighborhood walkability, the government can guide residents to travel actively and healthily, thereby reducing the risk of obesity and building a health-oriented city.

Thirdly, some travel attitudes and preferences have significant indirect effects on individual BMI through the mediating effect of commute mode. This indicates that individual obesity prevention should take account of travel attitudes and preferences like "the degree of preference for traveling by bus or metro" and "the degree of preference for traveling by car." Changing residents' travel attitudes and preferences, especially facilitating behavior change from using private motorized modes to using non-private motorized modes to commute and shaping preferences for these travel modes, may play an important role in reducing residents' BMI.

\subsection{Limitations and future research}

Although this paper has drawn some valuable conclusions, it may have some limitations. First, there may be bias in selecting the neighborhoods, which does not fully represent all neighborhoods in Guangzhou. There may be a non-probability sampling problem in the process of surveying, using the convenience sampling method. Therefore, some risks may exist in generalizing the conclusions and deducing them to other cities.

Second, our BMI indicators were based on self-reported questionnaires and self-report measures of individual height and weight may not accurately reflect objective measures. The respondents may overestimate or underestimate their health status, which could result in outcome misclassification. Future research should attempt to complement self-reports with objective measurement of health, i.e., height, weight, blood pressure.

Finally, the present findings suggest that neighborhood walkability and commute mode do affect 
individual BMI. However, our findings do not support the hypothesis that higher neighborhood walkability among residents of high-risk obesity results from non-private motorized commute mode. Longitudinal and controlled study designs are required to draw stronger causal conclusions on the relationship between neighborhood walkability and individual BMI. More work needs to be done by examining changes in travel attitudes and preferences and commute mode among residents moving neighborhood to another. Future research should cross-examine existing conclusions and enrich the theoretical and methodological framework.

\section{Acknowledgements}

This work was supported by the National Natural Science Foundation of China (41701169; 41871148), the Guangzhou Science and Technology Project (202102021041), and the Philosophy and Social Sciences Planning Project of Guangdong Province (GD17YSH01). The authors are grateful for the receipt of these funds. 


\section{References}

Adlakha, D., \& Parra, D. C. (2020). Mind the gap: Gender differences in walkability, transportation and physical activity in urban India. Journal of Transport and Health, 18, 100875.

Adlakha, D., Hipp, J. A., \& Brownson, R. C. (2016). Neighborhood-based differences in walkability, physical activity, and weight status in India. Journal of Transport and Health, 34, 485-499.

Administration of Sports of Guangdong Province. (2011). Sampling survey of national physique in Guangzhou in 2011. http://tyj.gd.gov.cn/

Alfonzo, M., Guo, Z., Lin, L., \& Day, K. (2014). Walking, obesity and urban design in Chinese neighborhoods. Preventive Medicine, 69, S79-S85.

An, R., Shen, J., Yang, Q. Y., \& Yang, Y. (2019). Impact of built environment on physical activity and obesity among children and adolescents in China: A narrative systematic review. Journal of Sport and Health Science, 82, 153-169.

Barnes, R., Winters, M., Ste-Marie, N., Mckay, H., \& Ashe, M. C. (2016). Age and retirement status differences in associations between the built environment and active travel behavior. Journal of Transport and Health, 43, 513-522.

Black, J. L., Macinko, J., Dixon, L. B., \& Fryer, G. E. (2010). Neighborhoods and obesity in New York City. Health and Place, 163, 489-499.

Bodea, T. D., Garrow, L. A., Meyer, M. D., \& Ross, C. L. (2009). Socio-demographic and built environment influences on the odds of being overweight or obese: The Atlanta experience. Transportation Research Part A: Policy and Practice, 434, 430-444.

Boisjoly, G., El-Geneidy, A., \& Wasf, R. (2018). How much is enough? Assessing the influence of neighborhood walkability on undertaking 10-minute walks. Journal of Transport and Land Use, 11, 143-151.

Bödeker, M., Finne, E., Kerr, J., \& Bucksch, J. (2018). Active travel despite motorcar access. A citywide, GIS-based multilevel study on neighborhood walkability and active travel in Germany. Journal of Transport and Health, 9, 8-18.

Bongiorno, C., Santucci, D., Kon, F., Santi, P., \& Ratti, C. (2019). Comparing bicycling and pedestrian mobility: Patterns of non-motorized human mobility in Greater Boston. Journal of Transport Geography, 80, 102501.

Cambra, P., \& Moura, F. (2020). How does walkability change relate to walking behavior change? Effects of a street improvement in pedestrian volumes and walking experience. Journal of Transport and Health, 16, 100797.

Cervero, R., \& Kockekman, K. (1997). Travel demand and the 3Ds: Density, diversity, and design. Transport Research Part D: Transport and Environment, 23, 199-219.

Chen, C., \& Menifield, C. E. (2017). An ecological study on means of transportation to work and obesity: Evidence from U.S. states. Transport Policy, 59, 174-180.

Chinese Center for Disease Prevention. (2015). The report on residents' nutrition and chronic diseases in China. Retreived from http://www.scio.gov.cn/xwfbh/xwbfbh/wqfbh/2015/33038/index.htm

Cohen, J. (1988). Statistical power analysis for the behavioral sciences, 2nd edition. New York: Routledge.

Dai, F., Diao, M. \& Sing, T. F. (2020). Effects of rail transit on individual travel mode shares: A twodimensional propensity score matching approach. Transportation Research Part D: Transport and Environment, 89, 102601.

Day, K. (2016). Built environmental correlates of physical activity in China: A review. Preventive Medicine Report, 3, 303-316.

Egset, K. S., \& Nordfjærn, T. (2019). The role of transport priorities, transport attitudes and situational factors for sustainable transport mode use in wintertime. Transport Research Part F: Traffic Psychology 
and Behavior, 62, 473-482.

Fang, J., Wen, Z. L., Zhang M. Q., \& Ren, H. (2014). Analyzing multilevel mediation using multilevel structural equation models. Advances in Psychological Science, 223, 530-539.

Frank, L. D., Iroz-Elardo, N., MacLeod, K. E., \& Hong, A. (2019). Pathways from built environment to health: A conceptual framework linking behavior and exposure-based impacts. Journal of Transport and Health, 12, 319-335.

Frank, L. D., Kerr, J., Sallis, J. F., Miles, R., \& Chapman, J. (2008). A hierarchy of sociodemographic and environmental correlates of walking and obesity. Preventive Medicine, 47(2), 172-178.

Frank, L. D., Saelens, B. E., Powell, K. E., \& Chapman, J. E. (2007). Stepping towards causation: Do built environments or neighborhood and travel preferences explain physical activity, driving, and obesity? Social Science \& Medicine, 65(9), 1898-1914.

Frank, L. D., Sallis, J. F., Saelens, B. E., Leary, L., Cain, K., Conway, T. L., \& Hess, P. M. (2010). The development of a walkability index: Application to the neighborhood quality of life study. British Journal of Sports Medicine, 44, 924-933.

Freeman, L., Neckerman, K., Schwartz-Soicher, O., Quinn, J., Richards, C., Bader, M. D., .. \& Konty, K. (2013). Neighborhood walkability and active travel walking and cycling in New York City. Journal of Urban Health, 904, 575-585.

Golan, Y., Wilkinson, N. L., Henderson, J., \& Weverka, A. (2019). Gendered walkability: Building a daytime walkability index for women. Journal of Transport and Land Use, 121, 50-526.

Hamidi, Z., \& Zhao, C. L. (2020). Shaping sustainable travel behavior: Attitude, skills, and access all matter. Transportation Research Part D: Transport and Environment, 88, 102566.

Hoffmann, C., Abraham, C., Skippon, S. M., \& White, M. P. (2018). Cognitive construction of travel modes among high-mileage car users and non-car users - A repertory grid analysis. Transport Research Part A: Policy and Practice, 118, 216-233.

Jones, A. (2015). Residential instability and obesity over time: The role of the social and built environment. Health and Place, 32, 74-82.

Joop, J. H., Mirjam, M., \& Rens, S. (2018). Multilevel analysis: Techniques and applications, 3rd edition. New York, USA: Routledge.

Kikuchi, H., Nakaya, T., Hanibuchi, T., Fukushima, N., Amagasa, S., Oka, K., ... \& Inoue, S. (2018). Objectively measured neighborhood walkability and change in physical activity in older Japanese adults: A five-year cohort study. International Journal of Environment Research and Public Health, 159, 1814-1827.

Kjær, T., Højgaard, B., \& Gyrd-Hansen, D. (2019). Physical exercise versus shorter life expectancy? An investigation into preferences for physical activity using a stated preference approach. Health Policy, 123(8), 790-796.

Kowaleski-Jones, L., Zick, C., Smith, K. R., Brown, B., Hanson, H., \& Fan, J. (2018). Walkable neighborhoods and obesity: Evaluating effects with a propensity score approach. SSM Population Health, 6, 9-15.

Leslie, E., Coffee, N., Frank, L. D., Owen, N., Bauman, A., \& Hugo, G. (2007). Walkability of local communities: Using geographic information systems to objectively assess relevant environmental attribute. Health and Place, 13, 111-122.

Liao, Y., Tsai, H. H., Wang, H. S., Lin, C. P., Wu, M. C., \& Chen, J. F. (2016). Travel mode, transportation-related physical activity, and risk of overweight in Taiwanese adults. Journal of Transport and Health, 32, 220-225.

Lindelöw, D., Svensson, A., Brundell-Freij, K., \& Hiselius, L. W. (2017). Satisfaction or compensation? The interaction between walking preferences and neighborhood design. Transportation Research Part 
$D, 50,520-532$.

Lin, T., Wang, D. G., \& Guan, X. D. (2017). The built environment, travel attitude, and travel behavior: Residential self-selection or residential determination? Journal of Transport Geography, 65, $11-122$.

Mavoa, S., Eagleson, S., Badland, H. M., \& Gunn, L. (2018). Identifying appropriate land-use mix measures for use in a national walkability index. Journal of Transport and Land Use, 11, 681-700.

Marquez, L., Macea, L. F., \& Soto, J. J. (2019). Willingness to change car use to commute to the UPTC main campus, Colombia: A hybrid discrete choice modeling approach. Journal of Transport and Land Use, 121, 335-353.

Matozinhos, F. P., Gomes, C. S., Andrade, A. C. D. S., Mendes, L. L., Pessoa, M. C., Friche, A. A. D. L., \& Velasquez-Melendez, G. (2015). Neighborhood environments and obesity among adults: A multilevel analysis of an urban Brazilian context. Preventive Medicine Report, 2, 337-341.

Matsumura, L. C., Garnier, H. E., \& Spybrook, J. (2013). Literacy coaching to improve student reading achievement: A multi-level mediation model. Learning and Instruction, 25, 35-48.

Moniruzzaman, M., Páez, A., Nurul, H. K. M., \& Morency, C. (2013). Mode use and trip length of seniors in Montreal. Journal of Transport Geography, 30, 89-99.

Munshi, T. (2016). Built environment and mode choice relationship for commute travel in the city of Rajkot, India. Transportation Research Part D: Transport and Environment, 44, 239-253.

Mytton, O., Ogilvie, D., Griffin, S., Brage, S., Wareham, N., \& Panter, J. (2018). Associations of active commuting with body fat and visceral adipose tissue: A cross-sectional population-based study in the UK. Preventive Medicine, 106, 86-93.

Nichani, V., Turley, L., Vena, J. E., \& McCornack, G. R. (2020). Associations between the neighborhood characteristics and body mass index, waist circumference, and waist-to-hip ratio: Findings from Alberta's Tomorrow Project. Health and Place, 64, 102357.

Pendola, R., \& Gen, S. (2007). BMI, auto use, and the urban environment in San Francisco. Health and Place, 132, 551-556. https://doi.org/10.1016/j.healthplace.2006.02.004

Peugh, J. L. (2010). A practical guide to multilevel modeling. Journal of School Psychology, 481, 85-112.

Sallis, J. F., Frank, L. D., Saelens, B. E., \& Kraft, M. K. (2004). Active transportation and physical activity: Opportunities for collaboration on transportation and public health research. Transport Research Part A: Policy Practice, 384, 249-268.

Sarkar, C, Gallacher, J., \& Webster, C. (2013). Built environment configuration and change in body mass index: The Caerphilly Prospective Study (CaPS). Health and Place, 19, 33-44.

Schoner, J., Chapman, J., Brookes, A., MacLeod, K. E., Fox, E. H., Iroz-Elardo, N., \& Frank, L. D. (2018). Bringing health into transportation and land use scenario planning: Creating a National Public Health Assessment Model N-PHAM. Journal of Transport and Health, 10, 401-418.

Schneider, R. J., \& Stefanich, J. (2018). Exploring the importance of detailed environment variables in neighborhood commute mode share models. Journal of Transport and Land Use, 11, 921-938.

Shashank, A., \& Schuurman, N. (2019). Unpacking walkability indices and their inherent assumptions. Health and Place, 55, 145-154.

Smargiassi, A., Plante, C., Morency, P., Hatzopoulou, M., Morency, C., Eluru, N., .. \& Requia, W. (2020). Environmental and health impacts of transportation and land use scenarios in 2061. Environmental Research, 187, 109622.

Smart, M. J. (2018). Walkability, transit, and body mass index: A panel approach. Journal of Transport and Health, 8, 193-201.

Stark, J., Singleton, P. A., \& Uhlmann, T. (2019). Exploring children's school travel, psychological wellbeing, and travel-related attitudes: Evidence from primary and secondary school children in Vienna, 
Austria. Travel Behavior and Society, 16, 118-130.

Stephen, W. R., \& Anthony, S. B. (2002). Hierarchical linear models: applications and data analysis methods, 2nd edition. London: SAGE Publications.

Su, S. L., Pi, J. H., Xie, H., Cai, Z. L., \& Weng, M. (2017). Community deprivation, walkability, and public health: Highlighting the social inequalities in land use planning for health promotion. Land Use Policy, 67, 315-326.

Sugiyama, T., Niyonsenga, T., Howard, N. J., Coffee, N. T., Paquet, C., Taylor, A. W., \& Daniel, M. (2016). Residential proximity to urban centers, local-area walkability and change in waist circumference among Australian adults. Preventive Medicine, 93, 39-45.

Sun, B. D., \& Yin, C. (2018). Relationship between multi-scale urban built environments and body mass index: A study of China. Applied Geography, 94, 230-240.

Sun, B. D., Yan, H., \& Zhang, T. L. (2017). Built environmental impacts on individual mode choice and BMI: Evidence from China. Journal of Transport Geography, 63, 11-21.

Tuckel, P., \& Milczarski, W. (2015). Walk score TM, perceived neighborhood walkability, and walking in the US. American Journal of Health Behavior, 392, 241-255.

Turrell, G., Hewitt, B. A., Rachele, J. N., Giles-Corti, B., \& Brown, W. J. (2018). Prospective trends in body mass index by main transport mode, 2007-2013. Journal of Transport and Health, 8, 183-192.

van Cauwenberg, J., Van Holle, V., De Bourdeaudhuij, I., Van Dyck, D., \& Deforche, B. (2016). Neighborhood walkability and health outcomes among older adults: The mediating role of physical activity. Health and Place, 37, 16-25.

van de Coevering, P., Maat, K., \& van Wee, B. (2018). Residential self-selection, reverse causality and residential dissonance. A latent class transition model of interactions between the built environment, travel attitudes and travel behavior. Transportation Research Part A: Policy and Practice, 118, 466-479.

Wang D., \& Lin T. (2014). Residential self-selection, built environment, and travel behavior in the Chinese context. Journal of Transport and Land Use, 7(3), 5-14.

Wang, F. H., Wen, M., \& Xu, Y. Q. (2013). Population-adjusted street connectivity, urbanicity and risk of obesity in the U.S. Applied Geography, 41, 1-14.

Wang, H., \& Yang, Y. Q. (2019). Neighborhood walkability: A review and bibliometric analysis. Cities, 93, 43-61.

Wasfi, R. A., Dasgupta, K., Eluru, N., \& Ross, N. (2016). Exposure to walkable neighborhoods in urban areas increases utilitarian walking: Longitudinal study of Canadians. Journal of Transport and Health, 34, 440-447.

Watson, K. B., Whitfield, G. P., Thomas, J. V., Berrigan, D., Fulton, J. E., \& Carlson, S. A. (2020). Associations between the National Walkability Index and walking among US adults - National Health Interview Survey, 2015. Preventive Medicine, 137, 106122.

Wee, B. \& Ettema, D. (2016). Travel behavior and health: A conceptual model and research agenda. Journal of Transport \& Health, 3(3), 240-248.

Weng, M., Ding, N., Li, J., Jin, X. F., Xiao, H., He, Z. M., \& Su, S. L. (2019). The 15-minute walkable neighborhoods: Measurement, social inequalities and implications for building healthy communities in urban China. Journal of Transport and Health, 13, 259-273.

Wey, W. M., \& Chiu, Y. H. (2013). Assessing the walkability of pedestrian environment under the transit-oriented development. Habitat International, 38, 106-118.

Xie, Y. (2013). Regression analysis, revised edition. Beijing: Social Science Academic Press.

Xu, Y. Q., \& Wang, F. H. (2015). Built environment and obesity by urbanicity in the U.S. Health and Place, 34, 19-29.

Xu, Y. Q., Wen, M., \& Wang, F. H. (2015). Multilevel built environment features and individual odds 
of overweight and obesity in Utah. Applied Geography, 60, 197-203.

Yang, W., Chen, H., \& Wang, W. (2020). The path and time efficiency of residents' trips of different purposes with different travel modes: An empirical study in Guangzhou, China. Journal of Transport Geography, 88, 102829.

Yang, W. Y., \& Cao, X. S. (2018). Examining the effects of the neighborhood built environment on $\mathrm{CO} 2$ emissions from different residential trip purposes: A case study in Guangzhou, China. Cities, 81, 24-34.

Yang, W. Y., Zhen, X. Y., Gao, W., \& Ouyang, S. S. (2020). An examination of the impact of neighborhood walking environments on the probability of overweight or obesity among residents of dense urban areas. Canadian Geographer, 64(4), 619-633.

Yencha, C. (2019). Valuing walkability: New evidence from computer vision methods. Transport Research Part A: Policy Practice, 130, 689-709.

Zhao, P. J. (2013). Too complex to be managed? New trends in peri-urbanization and its planning in Beijing. Cities, 30, 68-76.

Zhao, Z., \& Kaestner, R. (2010). Effects of urban sprawl on obesity. Journal of Health Economics, 296, 779-787.

Zhou, M., Tan, S. K., Tao, Y. H., Lu, Y, Z., Zhang, Z., Zhang, L., \& Yan, D. P. (2017). Neighborhood socioeconomics, food environment and land use determinants of public health: Isolating the relative importance for essential policy insights. Land Use Policy, 68, 246-253. 